\title{
O papel da mediação da informação na biblioteca escolar
}

\author{
The role of the information mediation in the school library
}

\begin{abstract}
Erica Mariza Correia
Mestranda em Gestão da Informação e do Conhecimento pelo Programa de Pós-Graduação em Ciência da Informação pela Universidade Federal de Sergipe - UFS, Brasil.

E-mail: ericamariza@hotmail.com

Cleide Aparecida Freires Belchior

Mestranda em Gestão da Informação e do Conhecimento pelo Programa de Pós-Graduação em Ciência da Informação pela Universidade Federal de Sergipe - UFS, Brasil.

E-mail: cleidelibra@yahoo.com.br

Janaina Ferreira Fialho Professora associada da Universidade Federal de Sergipe - UFS, Brasil. E-mail: janafialho@academico.ufs.br
\end{abstract}

\section{Resumo}

Esta pesquisa abordou o papel do bibliotecário no que tange a mediação da informação no ambiente da biblioteca escolar por meio de uma revisão narrativa de literatura. Parte da compreensão de que para que esse processo se desenvolva é necessário o apoio do profissional mediador da informação, assim como de espaços disponíveis para a ampliação e disseminação de saberes por meio da apropriação da informação. Para tanto, tem como objetivo geral avaliar o papel da mediação da informação na biblioteca escolar e abordar alguns temas como o papel da informação na sociedade da informação e do conhecimento; mediação e apropriação da informação no campo da Ciência da Informação e bibliotecas escolares como dispositivos informacionais. A metodologia utilizada foi a revisão narrativa de literatura, caracterizando-se como pesquisa bibliográfica, de natureza qualitativa. Observouse que o papel da mediação da informação produz maior eficácia com o auxílio de um profissional da informação, além disso, o acesso à informação e ampliação do conhecimento nesses espaços de saberes proporcionam maiores habilidades e competências nos sujeitos, utilizando-se da teoria da competência informacional. Sendo assim, a mediação da informação ocorre com a interferência desse profissional, seja nas trocas de ideias, na interação social, no compartilhamento de informações, com a participação ativa de sujeitos protagonistas, ou no processo de busca por aprendizados contínuos. O profissional da informação poderá fazer a diferença ao interferir ampliando o acesso, facilitando a apropriação e situando a biblioteca escolar como espaço de construção de significados e compartilhamento de saberes que geram conhecimentos produtivos.

Palavras-chave: Biblioteca escolar. Mediação da informação. Bibliotecário escolar.

\begin{abstract}
This research addresses the role of the librarian in terms of information mediation in the school library environment through a narrative literature review. It assumes that this process can only take place with the necessary support from the professional mediator of information, and with the spaces available for the expansion and dissemination of knowledge through the appropriation of information. To this end, its general objective is to evaluate the role of information mediation in the school library and to address some topics, such as the role of information in the information and knowledge society; mediation and appropriation of information in the field of Information Science; and school libraries as informational devices. The methodology used was literature review, characterized as a bibliographic research, of qualitative nature. It was observed that the role of mediation of information produces greater effectiveness with the help of an information professional; in addition, access to information and expansion of knowledge in these spaces provide greater skills in the subjects, according to information literacy theory. Thus, mediation of information occurs with this professional's interference, whether in the exchange of ideas, in social interaction, in the sharing of information, with the active participation of protagonist subjects, or in the search for continuous learning. The information professional can make a difference by expanding access, facilitating appropriation and placing the school library as a space for the construction of meanings and the sharing of productive knowledge.
\end{abstract}

Keywords: School library. Information mediation. School librarian.

Bibl. Esc. em R., Ribeirão Preto, v. 7, n. 2, p. 102-121, 2021.

DOI: 10.11606/issn.2238-5894.berev.2021.173203 


\section{Introdução}

Os estudos sobre a mediação da informação no campo da Ciência da Informação (CI) sinalizam o papel de destaque desta temática diante da abrangência do acesso à informação e da disseminação do conhecimento. Com o crescimento exponencial dos fluxos informacionais, tornou-se necessária a presença de um profissional que promova a gestão da informação, disponibilizando o seu acesso e evitando, assim, um movimento em direção à desinformação.

Reconhecendo as bibliotecas como dispositivos produtores de sentido para a realização de atividades culturais e acadêmicas, Rasteli e Cavalcante (2014, p. 44) afirmam que essas unidades informacionais "permitem o acesso à informação, observando a construção de significados vivenciados através da pesquisa, da leitura". Diante disso, a mediação da informação corresponde a uma das principais práticas do profissional da informação em bibliotecas e demais unidades de informação, principalmente com as novas configurações da informação como elemento construtivo do saber social.

Tendo em vista esses novos desafios na esfera informacional, a presente pesquisa centraliza a função pedagógica desempenhada pela biblioteca escolar (BE), atribuindo ao profissional bibliotecário papel essencial para o desenvolvimento da mediação e para a construção coletiva do conhecimento. Contudo, o posicionamento aqui adotado vai de encontro às pesquisas e práticas profissionais, que apontam para a falta de visibilidade do bibliotecário nos espaços de ensino e aprendizagem, causada sobretudo por antigas barreiras de ausência de recursos e de investimentos.

Este cenário pode ser facilmente observado na realidade encontrada nas bibliotecas brasileiras, que em muitos casos não contam com um profissional bibliotecário. Da mesma forma, a meta de universalização das bibliotecas nas instituições de ensino até o ano de 2020, estipulada pela Lei $\mathrm{n}^{\circ}$ 12.244, de 24 de maio de 2010, não conseguiu ser concretizada. Acrescenta-se à problemática da pesquisa a dificuldade em se reconhecer a biblioteca como unidade de pesquisa, socialização do conhecimento, interação social e compartilhamento de ideias; em suma, a biblioteca ainda não é vista como um espaço de promoção do aprendizado e da apropriação do saber.

Diante da relevância da discussão sobre o processo de mediação no âmbito da BE, o problema de pesquisa aqui colocado está em superar e mostrar como os profissionais da informação podem atuar como mediadores da informação, em outras palavras: de que forma a 
mediação do bibliotecário pode trazer resultados positivos e impactantes na aprendizagem dos alunos?

Como objetivo, busca-se apresentar, através de revisão da literatura, o papel da mediação da informação nas bibliotecas escolares. Porém, mais especificamente, como o fazer profissional do bibliotecário e sua atuação na BE podem contribuir no atual contexto de sociedade da informação e do conhecimento.

A pesquisa possui caráter bibliográfico e abordagem qualitativa. Primeiramente, são apresentados aspectos históricos sobre a sociedade da informação, destacando-se a importância de se saber utilizar os recursos informacionais dada a grande disponibilidade de informações. Em seguida, são abordados os conceitos pertinentes à mediação e à apropriação da informação no campo da CI. Por fim, são destacados os benefícios da utilização das BEs na ampliação e construção coletiva do conhecimento.

\section{O papel da informação na sociedade da informação e do conhecimento: um apontamento para a competência informacional}

A sociedade da informação e do conhecimento está presente na contemporaneidade, na qual a busca pela informação e pelo conhecimento tem modificado os campos social e econômico. Essa mudança está vinculada a um grande fluxo informacional disponibilizado em diferentes suportes e formatos, e com grande diversidade de fontes - em sua maioria em rede - , o que exige uma nova postura no fazer profissional do bibliotecário como profissional da informação.

Entende-se que esse cenário informacional desencadeia uma maior preocupação na busca, acesso, recuperação e, principalmente, no uso da informação. Essa realidade imputa aos sujeitos o acesso facilitado a milhares de informações, e nessa diversidade de fontes nem sempre a informação é confiável, eficaz e seletiva. Tal reflexão tem motivado as principais discussões e pesquisas na área da CI no que tange à análise crítica e reflexiva da informação, as quais devem seguir critérios de segurança e confiabilidade.

Sob essa perspectiva, Fachin (2013) entende que existe uma grande aceleração das informações disponibilizadas nos espaços eletrônicos, com crescente ampliação e disseminação do conhecimento. Contudo, destaca que, para que haja de fato geração de conhecimento, é 
necessária a promoção do ciclo dinâmico das fontes de informação, sendo fundamental a presença de um mediador, pois este "usa seus conhecimentos para criar ferramentas facilitadoras de acesso aos acervos informacionais, destinados a públicos distintos" (FACHIN, 2013, p. 27).

Neste cenário de grande circulação informacional em diversos suportes, sobretudo eletrônicos, o papel do profissional da informação é imprescindível, pois auxilia na organização, recuperação e uso informacionais, podendo proporcionar maior ganho de tempo e qualidade da informação aos usuários, e, consequentemente, otimizar os resultados de pesquisa.

Para a CI, a informação acompanhou toda a evolução social do homem, e o seu papel protagonizou as mudanças de paradigmas, interligando diferentes áreas do saber, institucionalizando a informação, contribuindo para a evolução da ciência e provocando debates interdisciplinares. Silva e Gomes (2015) ressaltam, entretanto, a pluralidade conceitual das principais percepções da informação no âmbito da CI, que advém das estreitas relações do conceito de informação com outras terminologias, a saber: documento, dado, mensagem, interação e estrutura social, comunicação e conhecimento, etc. (SILVA; GOMES, 2015).

Capurro (2017) sinaliza a recuperação da informação como um núcleo importante da CI, campo cujo desenvolvimento expressivo se deu a partir da década de 1950, graças aos aprimoramentos tecnológicos desenvolvidos após a Segunda Guerra Mundial. Lancaster (1993), por sua vez, atrela a recuperação da informação à questão dos vocabulários controlados e da busca por palavras nos textos.

Percebe-se, então, que a CI possui um papel essencial, principalmente por desenvolver debates e encontrar soluções para o bem coletivo, podendo ser caracterizada como uma ciência humana e social (ARAÚJO, 2014). Segundo o autor, a CI coloca a informação no cerne dos avanços teóricos e conceituais vinculados, por isso existe uma diversidade de modelos e compreensões da informação em diferentes campos de estudos, diferentes objetos empíricos com conceitos que variam em face ao diálogo com distintas áreas de estudo disciplinares (ARAÚJO, 2014).

Com o advento das Tecnologias da Informação e da Comunicação (TIC), o acesso à informação tornou-se ilimitado e em tempo real, sendo este último um aspecto positivo. No entanto, o volume das informações, e a veracidade e fidedignidade das suas fontes desencadearam preocupações e questionamentos quanto à sua qualidade. 
Nesse cenário, é evidente a importância do desenvolvimento de competências para se lidar com a informação, bem como de competências de mediação e apropriação pelo sujeito informacional. Essas capacidades representam demandas desafiadoras, porém cruciais, para que o usuário possa de fato acessar o valor da informação que têm à sua disposição, construindo assim um conhecimento verdadeiramente crítico.

Do inglês information literacy ${ }^{l}$, o conceito competência informacional foi traduzido por diversos pesquisadores brasileiros, apresentando diversidades terminológicas, mas foi Campello (2002), uma das principais pesquisadoras brasileiras na temática que o traduziu nesses termos. Como cerne de todos os estudos, está o conceito basilar apresentado pela Associação Americana de Biblioteconomia (ALA) em 1989, o qual conecta a competência informacional às habilidades de reconhecimento, localização, avaliação e uso da informação ${ }^{2}$.

Almeida (2016, p. 15), por sua vez, entende a competência informacional como "um conjunto de estratégias que podem ser utilizadas para distinguir os diferentes tipos de informação e o uso da informação de forma ética e legal”. Também associa o conceito à construção independente do seu próprio saber, a partir da análise dos dados colhidos, visão essa semelhante à partilhada por Belluzzo, Santos e Almeida Júnior (2014), que enxergam o desenvolvimento da competência informacional como um processo que se estende durante toda a vida, contribuindo para que o sujeito conquiste a sua autonomia e aproprie-se do conhecimento.

Para a autora, a mediação e a competência informacional criaram um vínculo indissociável com a presença das TIC na educação, transformando os processos de trabalho dos bibliotecários, principalmente na BE. Com a informação em rede, existe, além dos suportes físicos, uma interferência do bibliotecário no processo de pesquisa e acesso à informação pelo usuário, o que caracteriza a importância do bibliotecário como mediador (ALMEIDA, 2016).

Em suas reflexões, Almeida (2016) ainda reconhece maiores possibilidades no aprendizado, destacando que na sociedade da informação e do conhecimento, o crescimento informacional evidenciou a função educativa e social das bibliotecas, as quais são espaços de aprendizado e apropriação de conhecimentos. A centralidade da biblioteca também é

\footnotetext{
${ }^{1}$ Usado pela primeira vez em 1974 por Paul Zurkowsky, presidente da Associação de Indústrias da Informação nos Estados Unidos.

2 Comitê Presidencial sobre Competência Informacional: relatório final. Disponível em: http://www.ala.org/acrl/publications/whitepapers/presidential. Acesso em: 03 mar. 2021.
} 
Erica Mariza Correia, Cleide Aparecida Freires Belchior e Janaina Ferreira Fialho

identificada por Silva e Cunha (2016, p. 47): “os professores e pedagogos tornam-se também importantes para proposição de ações de mediação e incentivo à leitura. Tais atividades caracterizam fortemente o papel educativo da biblioteca e dos profissionais que nela atuam".

A nova configuração que esses profissionais passaram a representar contribui diretamente para a melhoria do processo de busca, recuperação e apropriação da informação. Considerando ainda que a informação faz parte do desenvolvimento da sociedade, principalmente em tempos de crise pandêmica mundial, a informação relevante e seletiva pode salvar vidas e ampliar o conhecimento da população. Portanto, quando o sujeito se apropria da informação, pode gerar um ciclo de conhecimento e disseminá-lo para o bem da coletividade.

\section{Aspectos da mediação e da apropriação da informação}

Dentre os estudos sobre a mediação da informação, é possível destacar o trabalho de Almeida Júnior (2015), que aborda o subjetivismo implícito no aprendizado. Segundo o autor, "o mundo que nos é mostrado, não é um reflexo, mas uma refração (assim como a informação)" (ALMEIDA JÚNIOR, 2015, p. 11). Dessa forma, existe uma identificação com o conhecimento construído por outrem, podendo-se, a partir dessa junção, aprimorar ainda mais os novos conhecimentos, envolvendo mediados e mediadores no seu processo de construção e apropriação.

Compreende-se que cada sujeito carrega o seu conhecimento tácito, advindo das suas experiências de mundo, convívio social e realidades individuais internalizadas. Porém, é evidente que a informação não existe sozinha, ela precisa de cada sujeito para poder ser disseminada para a coletividade, a qual complementa e amplia o conhecimento já existente devido ao seu caráter dinâmico e contínuo de comunicação. Sendo interpretada em diferentes momentos e por diferentes sujeitos, cada qual com suas singularidades, à informação são atribuídos diferentes significados, de acordo com os conhecimentos implícitos agregados a cada indivíduo.

Almeida Júnior (2009) destaca que a mediação está presente em todo o fazer do profissional da informação, implícita ou explicitamente, desde o armazenamento da informação até a sua disseminação, interferindo em todos os processos informacionais. Para o autor, a interferência pode ser lida como marco para a mediação, pois a mesma é "constante e indissociada do fazer do profissional da informação" (ALMEIDA JÚNIOR, 2009, p. 93). 
O papel da mediação da informação na biblioteca escolar

Seguindo o mesmo raciocínio, Silva (2015, p. 103) atribui ao processo de mediação a interferência e a intervenção conscientes por parte do mediador, a saber:

\begin{abstract}
um conjunto de práticas construtivas de intervenções e interferências regidas por intencionalidades, normas/regras, correntes teórico-ideológicas e crenças concebidas pelo profissional da informação em interação com os usuários no âmbito de suas realidades cotidianas e experienciais, indicando procedimentos singulares, coletivos e/ou plurais de acesso e uso da informação, estimulando à apreensão e apropriação para satisfação de necessidades de informação.
\end{abstract}

Considerando-se as diferentes concepções sobre mediação da informação na CI, e com base nos principais pesquisadores da área, o quadro 1 apresenta uma compilação de alguns conceitos de mediação importantes.

Quadro 1 - Principais conceitos de mediação da informação no âmbito da CI

\begin{tabular}{|c|l|l|}
\hline Ano & \multicolumn{1}{|c|}{ Autor } & \multicolumn{1}{c|}{ Conceito } \\
\hline 1999 & Bernard Lamizet & $\begin{array}{l}\text { A mediação representa o imperativo social essencial da } \\
\text { dialética entre o singular e coletivo, e da sua } \\
\text { representação em formas simbólicas (1999, p. 9). }\end{array}$ \\
\hline 2000 & Adriano Duarte Rodrigues & $\begin{array}{l}\text { [..] processo de interlocução ou interacção entre os } \\
\text { membros de uma comunidade, pelo qual se estabelece, } \\
\text { alimentam ou restabelecem laços de sociabilidade, } \\
\text { constituindo assim o mundo da vida. A linguagem e a acção } \\
\text { comum são os fatores privilegiados de mediação (2000, p. } \\
84) .\end{array}$ \\
\hline 2008 & $\begin{array}{l}\text { Oswaldo Francisco de Almeida } \\
\text { Júnior }\end{array}$ & $\begin{array}{l}\text { Toda ação de interferência - realizada pelo profissional da } \\
\text { informação - direta ou indireta; consciente ou } \\
\text { inconsciente; singular ou plural; individual ou coletiva; que } \\
\text { propicia a apropriação de informação que satisfaça, plena } \\
\text { ou parcialmente, uma necessidade informacional (2008. p. } \\
46)\end{array}$ \\
\hline 2015 & Lúcia Santaella & $\begin{array}{l}\text { O conceito de mediação não deve ser simploriamente } \\
\text { entendido como meio de comunicação e nem mesmo como } \\
\text { ambiente cultural e social que os meios criam. Mediação é, } \\
\text { sobretudo, um conceito epistemológico que envolve a } \\
\text { grandeza humana, que é também a nossa tragédia de só ter } \\
\text { acesso ao mundo físico, afetivo, sensório, perceptivo, } \\
\text { cognitivo, pela mediação dos signos (2011, p. 207-208). }\end{array}$ \\
\hline $\begin{array}{l}\text { A mediação é um conceito denso e que envolve fatores } \\
\text { diversos como o centro de informação, profissionais da } \\
\text { informação e usuários como uma tríade que demanda a } \\
\text { necessidade de uma construção social e interacionista, } \\
\text { compreendendo a informação como fenômeno } \\
\text { transformador, norteador e estimulante na construção de } \\
\text { novos conhecimentos (2015, p. 106). }\end{array}$ \\
\hline
\end{tabular}

Fonte: elaborado pelas autoras (2021).

De acordo com Almeida Júnior (2008), a mediação não está restrita ao atendimento ao usuário da informação, mas abrange outras atividades que antecedem a esse atendimento direto. Esse ponto reconhece a mediação da informação nas unidades de informação, sejam elas bibliotecas, arquivos, museus, assim como nas empresas, enfim, em locais onde ocorre um grande fluxo de informação formal e informal. 
Essa amplitude da mediação da informação no fazer profissional é denominada por Almeida Júnior e Santos Neto (2014) como a mediação para organização do conhecimento, de forma que é fundamental que se reconheça toda a potencialidade do profissional da informação como mediador, principalmente o mediador bibliotecário, por ser um profissional com "papel transformador em todos os ambientes dentro de uma biblioteca/instituição" (ALMEIDA JÚNIOR; SANTOS NETO, 2014, p. 101).

Almeida Júnior (2015) ainda destaca o papel do bibliotecário nos espaços de busca da informação, pois, a partir da grande demanda informacional, esse profissional vem mediar o complexo processo informacional presente em todas as ações da CI. Ainda segundo o autor, "a mediação não é um momento, mas um processo" (ALMEIDA JÚNIOR, 2015), pois, há vários suportes e sujeitos nele envolvidos, os quais, vale ressaltar, têm seu papel ativo na construção e apropriação da informação, seja na mediação implícita, seja na explícita.

A primeira, a mediação implícita, ocorre nos espaços dos equipamentos
informacionais em que as ações são desenvolvidas sem a presença física e imediata
dos usuários. Nesses espaços, como já observado, estão a seleção, o armazenamento
e o processamento da informação. A mediação explícita, por seu lado, ocorre nos
espaços em que a presença não seja física, como, por exemplo, nos acessos a distância
em que não é solicitada a interferência concreta e presencial do profissional da
informação (ALMEIDA JÚNIOR, 2009, p. 93).

Reforça-se de forma mais clara, a partir do conceito supracitado, a importância do profissional da informação como mediador, visto que atua de forma explícita e implícita em todo o processo de aquisição, tratamento, recuperação, disseminação e apropriação da informação. Além disso, entende-se que existem diversas informações em espaços paralelos, o que requer diferentes ações de interferência sob divergentes visões para mediar a informação. Subtende-se que identificar e atender uma necessidade informacional provoca novas dúvidas e gera saberes, para além de novas necessidades informacionais, surgindo assim novos conhecimentos.

Para que ocorra a apropriação da informação, além da interferência de vários elementos, é necessário que o sujeito construa conhecimento através de experiências sociais e esforços contínuos, tornando-se protagonista no processo de ampliação do conhecimento e ganhando autonomia no momento da apropriação. Vale ressaltar que o sujeito precisa ser ativo nesse processo para que a conexão com a informação seja concretizada e, dessa forma, possa haver a apropriação do saber (SANTOS NETO; BORTOLIN; ALMEIDA JÚNIOR, 2017). Nessa perspectiva, destaca-se a complexidade existente na apropriação, já que ela somente acontece quando altera o estado de conhecimento anterior do sujeito. 
Conforme os autores supracitados, as interações sociais e trocas de informações contribuem para a apropriação de saberes, já que essa troca é dinâmica e auxilia no aprendizado cotidiano. Além disso, a busca por conhecimento visa apoderar-se de tais informações para necessidades ímpares, atribuindo sentidos e transformando a essência do sujeito, o qual após apropriar-se de novos conhecimentos, terá a possibilidade de visualizar o mundo de outros âmbitos e dimensões e, se possível, repassar tais saberes de forma consciente para a coletividade.

\section{Biblioteca escolar como dispositivo informacional para a mediação da informação}

A biblioteca constitui uma unidade de informação essencial para a disseminação do conhecimento, tendo destaque o papel do bibliotecário, o qual atua com a informação como seu principal objeto de estudo e de trabalho. De acordo com Aguiar (1994b, p. 139), "o conceito de biblioteca está condicionado ao de agente cultural, com função específica e mantendo intercâmbio com as demais instituições sociais, o que implica um comprometimento social do profissional da biblioteca com a autoridade".

A BE deve, portanto, cumprir suas funções culturais e educativas com o apoio e a participação ativa do profissional bibliotecário no processo educacional, visto que, "à biblioteca escolar, porque ligada à instituição responsável pela educação formal, é atribuída a responsabilidade de formação de leitores”. (AGUIAR, 1994a, p. 101).

Importante salientar os benefícios que o espaço das bibliotecas proporciona aos estudantes. Na pesquisa desenvolvida por Baughman (2000 apud FIALHO; ANDRADE 2007, p. 27), realizada em Massachusetts (EUA) nos níveis fundamental e médio, foi possível comprovar que a qualidade da educação pública melhorou com a presença da BE e a atuação do bibliotecário escolar. Desse modo, em países onde a educação é tratada como prioridade, os espaços das bibliotecas recebem mais recursos e investimentos, e, entre outras características, possui diversidade de livros, local estruturado para a ampliação do aprendizado, e, na maior

parte dos casos, profissionais bibliotecários mediando o acesso à informação. Tais aspectos demonstram o valor essencial das bibliotecas no processo de ensino-aprendizagem.

Fialho e Andrade (2007) afirmam que o trabalho do profissional bibliotecário contribui positivamente e faz a diferença nas bibliotecas porque contribui para o melhor desenvolvimento das pesquisas e para a apropriação do conhecimento dos estudantes. Todavia, torna-se 
Erica Mariza Correia, Cleide Aparecida Freires Belchior e Janaina Ferreira Fialho

necessário o apoio da equipe pedagógica e o incentivo por parte dos professores, através de ações pedagógicas conjuntas e coordenadas. $\mathrm{O}$ acesso à informação, contudo, não fica circunscrito aos muros da biblioteca, pois o conhecimento ocorre nas experiências cotidianas, como conhecimento de mundo e interação social, o chamado conhecimento implícito na construção de saberes (FIALHO; ANDRADE, 2007).

Além dos benefícios do acesso à informação nos espaços das bibliotecas, há também o desenvolvimento por meio da leitura, motivando os alunos e despertando a curiosidade com a diversidade de livros disponíveis, contribuindo para a formação de sujeitos mais críticos e reflexivos. Para Nunes (2020) a BE é essencial para a formação de leitores mais críticos e reflexivos, pois é uma unidade de informação com capacidade de inserir ações de promoção à leitura.

\begin{abstract}
A leitura não se resume apenas à leitura obrigatória, aquela que é feita por indicação ou exigência do professor, mas deve ser vista também como uma atividade prazerosa que desperte a atenção e o prazer do leitor. O incentivo à leitura não é uma obrigação apenas da escola, pois essa iniciativa deve partir também dos bibliotecários e também dos pais (NUNES, 2020, n.p.).
\end{abstract}

A autora também salienta a necessidade de se atribuir responsabilidades aos docentes, os quais precisam se somar aos bibliotecários e desenvolver suas funções como educadores e mediadores. Dessa forma, abre-se espaço para uma participação conjunta e ativa, que desperte o gosto pela leitura e demais aprendizados advindos de saberes diversos, dando a mediação o poder de apresentar e criar laços perenes entre o livro e o aluno (NUNES, 2020).

Sendo a leitura o veículo através do qual o cidadão adquire conhecimento e se apropria de novas informações, a biblioteca contribui para torná-lo mais consciente das transformações existentes e o auxilia no processo de ensino-aprendizagem.

\footnotetext{
se as crianças, desde as séries iniciais, já usassem na sua rotina escolar as bibliotecas e o letramento informacional o ganho seria para o resto da vida. Pois, seria possível uma leitura sob os moldes da crítica, visto que esse modelo permite a formação de visões de mundo diversificadas, alavancando em um desenvolvimento de valores e crenças mais reflexivos sobre a realidade (TEIXEIRA; SANTOS, 2016, p. 23).
}

Nessa perspectiva, o sujeito já iniciaria o acesso à educação com fatores que auxiliariam no desenvolvimento crítico e cognitivo, já que as crianças teriam contato com o letramento desde cedo. Esse contato precoce com a leitura traria maior independência e autonomia no processo de aprendizagem, formando indivíduos com maior capacidade reflexiva ante a complexidade existente na vida humana. Dessa maneira, o bibliotecário assume papel essencial para a efetivação da BE ativa e geradora de conhecimento, o que levanta a urgência de reflexões 
sobre a falta de investimentos e recursos que poderiam proporcionar uma significativa melhoria da educação.

Com ênfase na problemática da falta de investimentos, Teixeira e Santos (2016, p. 23) pontuam que "a escola pode até possuir uma biblioteca, todavia não se sabe o que fazer com ela”. Milanesi (1986, p. 85 apud TEIXEIRA; SANTOS, 2016, p. 23), defende que a valorização das bibliotecas precisa começar na melhoria da qualidade das escolas, através da adequação do seu espaço e da facilitação do acesso, visto que no atual sistema escolar não há a valorização desse ambiente educacional, o qual precisa de investimentos, recursos e profissionais capacitados para que sua contribuição torne-se mais relevante no processo de ensinoaprendizagem.

Segundo Cortes, Cavalache e Fernandes (2018), as bibliotecas escolares têm por função servir de apoio pedagógico às pesquisas escolares e às ações de incentivo à leitura, extensivas às ações culturais ali trabalhadas. Nesse sentido, pode-se ressaltar o caráter dinâmico do processo de mediação da informação, à medida que:

A biblioteca escolar é unidade de informação social e promotora de várias oportunidades em desenvolver pesquisas por meio do acesso a artigos, teses e dissertações que serão usadas como fonte de informações para o embasamento teórico dos trabalhos dos alunos (CORTES; CAVALACHE; FERNANDES, 2018, p. 9).

No entanto, a ausência de institucionalização das bibliotecas escolares e a sua precarização abre espaço para interpretações como a de Antunes (1993, p. 188), que afirma que "a BIBLIOTECA ESCOLAR ainda vai surgir [...] porque falta o indispensável, o mais importante, o que dá sustentáculo a esta instituição - uma POLÍTICA que garanta a presença da biblioteca na escola, sua manutenção e constante atualização.

Segundo a autora, "é preciso que as bibliotecas sejam criadas por lei, com recursos orçamentários para que seu funcionamento seja garantido" (ANTUNES, 1993, p. 188-189), de maneira que este espaço seja visto como imprescindível na ampliação do aprendizado e facilitador na construção do saber.

De uma maneira geral, pode-se entender que a BE está vinculada a uma escola e às suas regras institucionais, sendo muitas as barreiras para reconhecê-la como um aporte dinâmico de recursos para a aprendizagem, organizada de forma a se integrar com a sala de aula no desenvolvimento do currículo escolar. Essas barreiras estão em geral vinculadas à falta de verbas e engajamento nas ações pedagógicas, fatores esses que afastam o público em geral. 
Erica Mariza Correia, Cleide Aparecida Freires Belchior e Janaina Ferreira Fialho

Antunes (1993, p. 16) comenta que a biblioteca "precisa ser vista como um novo espaço na escola e, mais do que isto, como uma oportunidade de fortalecimento do ensino, do convívio com a leitura, com o livro, com a inovação e contribuindo com o surgimento do leitor crítico, criativo e independente". Consequentemente, "o reconhecimento da BE como "centro dinâmico de recursos para a aprendizagem', destaca o acesso à informação na escola como o suporte para a qualificação do ensino, a formação do adulto leitor, pessoa independente e que busca, continuamente, seu aperfeiçoamento" (ANTUNES, 1993, p. 190).

Dessa forma, ressalta-se a importância do processo de mediação da informação no ambiente da BE, inserindo ações promovidas e conjugadas entre o bibliotecário e o corpo docente, com estratégias que promovam o incentivo à leitura, à pesquisa escolar e à cultura. Assim, a BE atua também como espaço onde se desenvolve a inter-relação do profissional da informação com a equipe pedagógica da escola em benefício dos seus alunos.

\section{Mediação da informação em bibliotecas escolares}

Nesse estudo, ressalta-se os benefícios do acesso às bibliotecas escolares e a sua contribuição para o aprendizado escolar ampliando a sua função social. Rasteli e Cavalcante (2014) abordam a temática considerando que a biblioteca dispõe de espaços e recursos nos quais circulam a informação, auxiliando na apropriação de conhecimentos, e, em meio a esse processo, encontra-se o profissional da informação como agente mediador no trabalho colaborativo que visa a eficácia do acesso à informação e construção dos saberes para a apropriação da informação e construção do conhecimento pelo usuário.

Porém, é imprescindível frisar que os espaços das bibliotecas são disseminadores de conhecimentos, permitindo acesso à informação, à leitura, e à produção de sentidos significativos. Para tanto, é importante destacar a necessidade de um processo de mediação cultural, sendo igualmente necessários a interação social e o diálogo entre os sujeitos, os quais permitem a troca de conhecimentos e sentimentos e agrupam os sentidos de cada cultura.

Ademais, conforme afirmam Rasteli e Cavalcante (2014, p. 46), “apropriar-se da informação implica, dessa forma, apropriar-se dos dispositivos informacionais", e entre tais dispositivos estão as bibliotecas, as quais se constituem de saberes que deverão ser repassados para a sociedade, a fim de reforçar que o ato do conhecimento, da reflexão, da interação e da interpretação auxiliam na transformação do sujeito e de sua autonomia, o qual poderá 
compartilhar conhecimentos e socializar saberes qualitativos.

A BE também possui o papel de manter preservadas as informações histórico-culturais, para que tais conhecimentos não se percam com o tempo e se mantenham relevantes para a sociedade. O mediador é um importante colaborador nesse processo de aprendizagem, no qual o sujeito precisa ser ativo, pois o mediador sozinho não promove transformação, por isso a relevância da interação social, assim, como afirmam os autores, as bibliotecas são espaços de apropriação de conhecimento e inúmeros aprendizados.

Considerando a informação como ponto inicial para adquirir conhecimento, é importante considerar que não basta acessá-la, mas sim saber utilizá-la para promover transformações e melhorias sociais. Wilson (1977) já apontava a importância da mudança do paradigma do acesso para o uso da informação, de um acesso físico para um intelectual. Para Belluzzo, Santos e Almeida Júnior (2014), faz-se necessário abordar aspectos relevantes da avaliação, como uma forma de melhorar o processo de aprendizagem contínua, não apenas em uma única atividade ou momento, pois o sujeito adquire conhecimentos sistematicamente, e não em momentos preestabelecidos.

Cada dia, cada atividade são oportunidades para a reflexão e apropriação do saber. Portanto, nota-se que medir o conhecimento de outrem é um aspecto subjetivo, por isso, tais autores destacam o desenvolvimento de habilidades e competências, além disso, a avaliação deve ocorrer a cada progresso concluído (BELLUZZO; SANTOS; ALMEIDA JÚNIOR, 2014).

Por fim, para avaliar as competências e habilidades de um sujeito, verifica-se a sua capacidade de apropriação de informação internalizada, o conhecimento adquirido e transformado em novas possibilidades, novos posicionamentos críticos e reflexivos, sendo ativo no processo de aprendizagem, construindo novos saberes e sabendo buscar as informações mais relevantes em meio a tantas possibilidades informacionais. 


\section{Metodologia}

Esta pesquisa traz uma revisão da literatura sobre mediação da informação e BE, explorando os principais autores da CI e discutindo a temática nas seções e subseções do corpus da pesquisa. Carvalho, Duarte, Menezes e Souza (2019, p. 37) apontam que a pesquisa de revisão narrativa de literatura "utiliza fontes bibliográficas ou material elaborado, como livros, publicações periódicas, artigos científicos, impressos diversos ou, ainda, textos extraídos da internet", sendo assim, um tipo de pesquisa mais acessível aos pesquisadores, os quais precisam ser mais cautelosos com relação à veracidade das inúmeras informações disponíveis.

A pesquisa faz uso de uma abordagem qualitativa, pois "trabalha predominantemente com dados qualitativos, isto é, a informação coletada pelo pesquisador não é expressa em números" (DALFOVO; LANA; SILVEIRA, 2008, p. 9). Desse modo, a pesquisa não faz uso de dados objetivos coletados, mas caracteriza-se pela subjetividade e complexidade vivenciada por diferentes sujeitos em diversos grupos sociais.

As fontes de informação consultadas provêm de publicações científicas publicadas em sites validados pela academia; de livros; e do Banco de Teses e Dissertações (BDTD), buscando identificar os principais diálogos em torno da temática. A análise das fontes foi realizada por meio de leitura sistemática, sendo selecionados os trabalhos a partir das palavras-chave: mediação da informação, apropriação da informação, BE e Ciência da Informação.

Foram analisadas teorias, conceitos, aspectos cognitivos, reflexões e discussões acerca da temática da mediação e apropriação da informação e aspectos das bibliotecas escolares, relacionando ambas as temáticas à área da CI. 


\section{Resultados e discussões}

A partir dos conceitos e características observados no decorrer da pesquisa, infere-se que a mediação da informação possui valores relevantes, consubstanciados pelo imprescindível auxílio do profissional mediador da informação. Do mesmo modo, um comum entendimento entre autores, revela a necessidade de reconhecimento da importância da biblioteca como dispositivo informacional e de implementação de melhorias para sua maior atuação e visibilidade para com a sociedade.

Diante disso, Fachin (2013, p. 35) afirma que, “o constante consumo de informação pela sociedade demandou diversas funcionalidades no processo de mediação. Uma delas é o atendimento diversificado para cada usuário, almejando atender suas necessidades específicas”. Nesse sentido, percebe-se que a mediação é um processo complexo que requer uma interação social e troca de ideias e envolve as especificidades individuais, necessitando, portanto, de um profissional da informação que facilite a ampliação do conhecimento e auxilie na construção do saber. Vale ressaltar a importância que possui o mediador da informação, já que segundo Fachin (2013), há um

[...] processo de comunicação que representa o elo existente entre o mediador e o usuário no processo de mediação. $\mathrm{O}$ mediador age como um facilitador, reduzindo o tempo de busca e a espera, possibilitando a obtenção de informações confiáveis (por conhecer fontes de informação de credibilidade), potencializando o uso dessa informação (FACHIN, 2013, p. 38).

Diante disso, torna-se necessário que os espaços de disseminação de conhecimentos possuam mais recursos e aperfeiçoamentos para a abrangência de temáticas que precisam ter mais visibilidade e investimentos, pois ao apropriar-se de saberes, os sujeitos adquirem também desenvolvimento crítico, tornando-se protagonistas nas suas conquistas, sendo ativos e reflexivos em seu papel na sociedade.

Os diálogos de Belluzzo, Santos e Almeida Júnior (2014, p. 67) destacam que “a mediação da informação, assim como a competência em informação, são ações de interferências realizadas por mediadores no processo de ensino-aprendizagem de competências e habilidades informacionais em uma biblioteca, por exemplo". Então, nota-se que o processo de mediação tem um intuito de ampliar o acesso à informação, tornando-se um fator crucial em espaços disseminadores de saberes, pois, tais profissionais trabalham como facilitadores da informação e favorecem a busca por melhoria no aprendizado. 
Por outro lado, Nascimento, Moro-Cabero e Valentim (2015, p. 12) salientam "que a mediação da informação ocorre somente quando há a apropriação da informação, isto significa que só haverá a mediação da informação se o usuário conseguir assimilar a informação acessada". Ou seja, sem a devida compreensão, o sujeito não conseguirá absorver informação nova e seu estado de conhecimento se manterá inalterado.

Portanto, a temática identifica o caráter essencial da busca por informações de qualidade e do desenvolvimento de competências e habilidades, ao passo que reforça a necessidade de mais espaços que disseminem a informação. Além disso, percebe-se que o profissional da informação possui grande relevância na organização informacional e no desenvolvimento da competência informacional dos sujeitos, ao ensinar os alunos a localizarem, usarem e avaliarem as informações, principalmente no meio eletrônico. Por isso, uma melhor promoção do conhecimento passa por um maior investimento nesse profissional.

\section{Considerações finais}

Respondendo à pergunta inicial da pesquisa, é possível afirmar que a ação coordenada e parceira do bibliotecário na escola pode trazer resultados significativos para a aprendizagem dos alunos, seja no âmbito da leitura, da pesquisa escolar e das ações culturais. A partir dos conceitos e características observados no decorrer da pesquisa, infere-se que a mediação da informação pelo bibliotecário possui valores relevantes, e que há a necessidade de reconhecimento da importância da biblioteca como dispositivo informacional e de implementação de melhorias para sua maior atuação e visibilidade social.

Diante disso, Fachin (2013, p. 35) afirma que, “o constante consumo de informação pela sociedade demandou diversas funcionalidades no processo de mediação. Uma delas é o atendimento diversificado para cada usuário, almejando atender suas necessidades específicas". Nesse sentido, percebe-se que a mediação é um processo complexo que requer interação social, troca de ideias e envolve a especificidade dos sujeitos no acesso à informação, necessitando de um profissional que facilite na ampliação do conhecimento e auxilie na construção do saber.

Vale ressaltar a importância do profissional bibliotecário enquanto mediador da informação no espaço escolar, já que age como facilitador, auxiliando na confiabilidade das informações (FACHIN, 2013). Diante disso, torna-se necessário que as bibliotecas escolares possuam mais recursos físicos e de pessoal nas estruturas formais de ensino, sobretudo na rede 
pública. A situação no Brasil nesse quesito deixa muito a desejar, apesar de algumas iniciativas bem sucedidas encontradas na literatura.

Esta pesquisa buscou evidenciar como a relação entre fatores como a aceleração do fluxo de informações na sociedade do conhecimento, a mediação da informação, os espaços ampliadores e os facilitadores de conhecimento, como as BEs, é relevante para a apropriação do conhecimento, para a adequada apropriação das informações e para a disseminação de saberes.

Contudo, o grande fluxo informacional, sozinho, não traduz-se em eficaz disseminação de saberes, sendo necessária a ampliação do número de espaços, como museus e arquivos, e profissionais capacitados, através da mediação, para que a melhoria da educação ocorra de fato. Da mesma forma, os marcos institucionais colocados juridicamente precisam ser respeitados enquanto políticas de médio a longo prazo, pois, caso contrário, representarão letra morta, incapaz de se inserir na realidade.

As discussões aqui colocadas não esgotaram todas as dimensões dessa complexa realidade, sendo necessário que demais pesquisas deem continuidade sobre o tema, ampliando o debate sobretudo acerca da mediação do bibliotecário nas unidades de informação.

\section{Referências}

AGUIAR, Vera Teixeira. Biblioteca e formação de leitores. In: BRASIL. MINISTÉRIO DA EDUCAÇÃO E DO DESPORTO. A formação do leitor: o papel das instituições de formação do professor para a educação fundamental. São Paulo: Moderna, 1994a. p.101.

AGUIAR, Vera Teixeira. Conclusões do seminário nacional sobre formação do leitor: o papel das instituições de formação do professor para a educação fundamental. In: BRASIL. MINISTÉRIO DA EDUCAÇÃO E DO DESPORTO. A formação do leitor: o papel das instituições de formação do professor para a educação fundamental. São Paulo: Moderna, 1994b. p.139.

ALMEIDA JÚNIOR, Oswaldo Francisco de. Mediação da informação: ampliando o conceito de disseminação. In: VALENTIM, Marta Lígia Pomim. Gestão da informação e do conhecimento no âmbito da Ciência da Informação. São Paulo: Polis: Cultura Acadêmica, 2008. p.41-54.

ALMEIDA JÚNIOR, Oswaldo Francisco de. Mediação da Informação: um conceito atualizado. In: BORTOLIN, S.; SANTOS NETO, J. A.; SILVA, R. J. (org.). Mediação oral da informação e da leitura. Londrina: ABECIN, 2015. p. 9-32. 
ALMEIDA JÚNIOR, Oswaldo Francisco de. Mediação da informação e múltiplas linguagens. Pesq. Bras. Ci. Inf., "Tendências da Pesquisa Científica em Ciência da Informação - TPBCI", Brasília, v.2, n.1, p.89-103, jan. /dez. 2009. Disponível em:

http://www.brapci.inf.br/_repositorio/2010/01/pdf_9aa58ba510_0007871.pdf. Acesso: 06 abr. 2020.

ALMEIDA JUNIOR, Oswaldo Francisco de; SANTOS NETO, João Arlindo dos. Mediação da informação e a organização do conhecimento: interrelações. Informação \& Informação, Londrina, v. 19, n. 2, 2014. Disponível em:

http://www.uel.br/revistas/uel/index.php/informacao/article/view/16716/pdf_25. Acesso em: 12 dez. 2020.

ALMEIDA, Regina Oliveira de. Mediação e letramento informacional: algumas considerações. Revista Analisando em Ciência da Informação: RACin, João Pessoa, v. 4, n. 2, p. 1-20, jul./dez. 2016. Disponível em: https://brapci.inf.br/index.php/res/v/80829. Acesso em: 12 out. 2020.

ANTUNES, Walda de Andrade. Curso de capacitação do professor regente de biblioteca. Brasília: Walda Antunes Consultorias, 1993, 222 p.

ARAÚJO, Carlos Alberto Ávila Araújo de. O que é Ciência da Informação?. Informação \& Informação, Londrina, v. 19, n. 1, p. 01-30, jan./abr. 2014. Disponível em:

http://www.uel.br/revistas/uel/index.php/informacao/article/viewFile/15958/14205. Acesso em: 12 dez. 2020.

BELLUZZO, Regina Célia Baptista Belluzzo; SANTOS, Camila Araújo dos; ALMEIDA JÚNIOR, Oswaldo Francisco de. A competência em informação e sua avaliação sob a ótica da mediação da informação: Reflexões e aproximações teóricas. Informação \& Informação, Londrina, v. 19, n. 2, p. 60-77, maio/ago. 2014. Disponível em:

http://www.uel.br/revistas/uel/index.php/informacao/article/view/19995/pdf_21. Acesso em: 12 dez. 2020.

CAPURRO, Rafael. Prefácio. In: OLIVEIRA, Eliane Braga de; RODRIGUES, GeorgeteMedleg (org.). Memória: interfaces no campo da informação. Brasília: Ed. da UnB, 2017. p. 10-14.

CAMPELLO, Bernadete. A competência informacional na educação para o século XXI. In: Biblioteca escolar: temas para uma prática pedagógica. Belo Horizonte: Autêntica, 2002. p. 9-11.

CARVALHO, Luis Osete Ribeiro; DUARTE, Francisco Ricardo; MENEZES, Afonso Henrique Novaes; SOUZA, Tito Eugênio Santos. Metodologia científica: teoria e aplicação na educação a distância. Livro digital. Petrolina-PE, 2019.83 p. Disponível em: https://portais.univasf.edu.br/dacc/noticias/livro-univasf/metodologia-cientifica-teoria-eaplicacao-na-educacao-a-distancia.pdf. Acesso em: 28 jul. 2020.

CORTES, Vanderléa Nóbrega Azevedo; CAVALACHE, Lucas Vinícius Junqueira; FERNANDES, Raquel Gonçalves da Silva. Promoção do letramento informacional para qualificação de docente: trabalho colaborativo entre biblioteca e professores. In: SIMPÓSIO INTERNACIONAL DE EDUCAÇÃO E COMUNICAÇÃO, 9., 2018. Aracaju. Anais [...]. Aracaju: Universidade Tiradentes, 2018. Disponível em: 
O papel da mediação da informação na biblioteca escolar

https://www.eventos.set.edu.br/index.php/simeduc/article/view/9488/4129. Acesso em: 26 maio 2020.

DALFOVO, Michael Samir; LANA, Rogério Adilson; SILVEIRA, Amélia. Métodos quantitativos e qualitativos: um resgate teórico. Revista Interdisciplinar Científica Aplicada, Blumenau, v.2, n.4, p. 01-13, Sem II. 2008. Disponível em: https://rica.unibes.com.br/rica/issue/view/18. Acesso em: 12 nov. 2020.

FACHIN, Juliana. Mediação da informação na sociedade do conhecimento. Biblios: Revista do Instituto de Ciências Humanas e da Informação, Rio Grande, v. 27, n. 1, p. 25-41, jan./jun. 2013. Disponível em: https://periodicos.furg.br/biblos/article/view/3096. Acesso em: 12 abr. 2020.

FIALHO, Janaina Ferreira; ANDRADE, Maria Eugênia Albino. Comportamento informacional de crianças e adolescentes: uma revisão de literatura estrangeira. Ciência da Informação, Brasília, v. 36, n. 1, p. 20-34, jan./abr. 2007. Disponível em: https://www.scielo.br/scielo.php?script=sci_abstract\&pid=S010019652007000100002\&nrm=iso\&tlng=pt. Acesso em: 20 nov. 2020.

LAMIZET, Bernard. La médiation culturalle. Paris: L'Harmattan, 1999.

LANCASTER, F. W. Indexação e resumos: teoria e prática. Brasília: Briquet de Lemos/Livros, 1993.

NASCIMENTO, Natália Marinho do; MORO-CABERO, Maria Manuela; VALENTIM, Marta Lígia Pomim. Mediação da informação em ambientes empresariais com enfoque nos fluxos de informações. In: ENCONTRO DE PESQUISA EM INFORMAÇÃO E MEDIAÇÃO, 2., 2015. Anais [...]. Londrina: UFPR, 2015. Disponível em: http://www.periodicos.ufsc.br/index.php/eb. Acesso em: 12 jul. 2020.

NUNES, Martha Suzana Cabral. Mediação da leitura na biblioteca escolar: práticas e fazeres na formação de leitores. Perspectivas em Ciência da Informação, Belo Horizonte, v. 25, n. 2, abr./jun. 2020. Disponível em:

https://www.scielo.br/scielo.php?script=sci_arttext\&pid=S1413-99362020000200003. Acesso em: 20 dez. 2020.

RASTELI, Alessandro.; CAVALCANTE, Lídia Eugênia. Mediação cultural e apropriação da informação em bibliotecas públicas. Encontros Bibli: revista eletrônica de biblioteconomia e ciência da informação, Florianópolis, v. 19, n. 39, p. 43-58, jan./abr. 2014. Disponível em: https://periodicos.ufsc.br/index.php/eb/article/view/1518-2924.2014v19n39p43. Acesso em: 20 nov. 2020.

RODRIGUES, Adriano Duarte. Dicionário breve da informação e da comunicação. Lisboa: Presença, 2000.

SANTAELLA, Lucia. Linguagens líquidas na era da mobilidade. 2. ed. São Paulo: Paulus, 2011.

SANTOS NETO, João Arlindo dos; BORTOLIN, Sueli; ALMEIDA JÚNIOR, Oswaldo Francisco de. A concepção de apropriação da informação nos periódicos da área "Comunicação e Informação" e anais do ENANCIB. In: ENCONTRO NACIONAL DE 
PESQUISA EM CIÊNCIA DA INFORMAÇÃO, 18., 2017.Anais [...]. Marília, SP, 2017. Disponível em: https://brapci.inf.br/index.php/res/v/105333. Acesso em“20 nov. 2020.

SILVA, Jonathas Luiz Carvalho; GOMES, Henriette Ferreira. Conceitos de informação na ciência da informação: percepções analíticas, proposições e categorizações. Informação \& Sociedade: Estudos, João Pessoa, v. 25, n. 1, p. 145-157, jan./abr. 2015. Disponível em: https://periodicos.ufpb.br/ojs2/index.php/ies/article/view/145/13200. Acesso em: $12 \mathrm{dez}$. 2020.

SILVA, Judson Daniel Oliveira da; CUNHA, Jacqueline de Araújo. O papel educativo da biblioteca escolar no contexto do Plano Nacional de Educação. Encontros Bibli: revista eletrônica de biblioteconomia e ciência da informação, Florianópolis, v. 21, n. 46, p. 45-58, maio/ago., 2016. Disponível em: https://periodicos.ufsc.br/index.php/eb/article/view/15182924.2016v21n46p45. Acesso em: 15 jul. 2020.

SILVA, Jonathas Luiz Carvalho. Percepções conceituais sobre mediação da informação.

InCID: Revista de Ciência da Informação e Documentação, Ribeirão Preto, v. 6, n. 1, p. 93 108, mar./ago. 2015. Disponível em:

http://www.revistas.usp.br/incid/article/view/89731/96288. Acesso em: 04 jun. 2020.

TEIXEIRA, C. A.; SANTOS, A. P. dos. A importância da leitura e da biblioteca no processo de Letramento Informacional. In: GOMES, Suely Henrique de Aquino [et al.]. Letramento Informacional: educação para a informação [recurso eletrônico]. Educação para informação. p. 15-34. Goiânia: Gráfica UFG, 2016.

WILSON, P. Public Knowledge, private ignorance: toward a library and information policy. Westport: Greenwood Press, 1977. 